\title{
Gestão do espaço organizacional
}

Mônica de Aguiar Mac-Allister da Silva | monica.macallister@ufba.br

Em campos como Administração e Estudos Organizacionais, espaço é eventualmente tratado e frequentemente esquecido. Espaço organizacional é, na maioria das vezes, considerado contexto e reduzido à dimensão física, e, por vezes, tomado como objeto composto de múltiplas e imbricadas dimensões e escalas. Para gestão, espaço organizacional tende a ser identificado como forma voltada principalmente para a função produtiva, muito embora haja desvios dessa tendência, por meio dos quais o espaço organizacional pode até se converter em complexo. 0 tema gestão do espaço organizacional é tratado quase sempre como secundário, e mesmo assim em publicações dispersas, requerendo sistematização e consolidação. Nessa visão construída com base em Física, Geografia, Arquitetura e Urbanismo, e, a partir de 1995, em Administração e nos Estudos Organizacionais, Mônica de Aguiar Mac-Allister da Silva (UFBA) indica os seguintes livros.

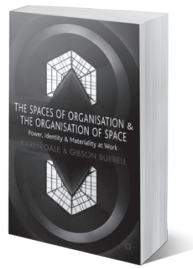

\section{THE SPACES OF ORGANISATION \& THE ORGANISATION} OF SPACE: Power, identity \& materiality at work

Karen Dale e Gibson Burrell. Basingstoke: Palgrave Macmillan, 2008. 328 p.

Este livro trata do espaço como local de trabalho, e mais exatamente como algo essencialmente físico no qual se processa o trabalho e, em correlato, a organização. Para os autores, o espaço (físico) organizacional, por um lado, é organizado sob a influência dos valores organizacionais e, por outro lado, influencia os indivíduos e suas identidades, e ainda a organização na sua totalidade e nos seus objetivos.

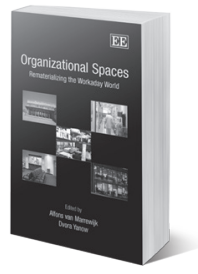

\section{ORGANIZATIONAL SPACES: Rematerializing the workaday world}

Alfons Van Marrewijk e Dvora Yanow (Eds.). Cheltenham (UK)/Northampton, Massachusetts (USA): Edward Elgar Publishing, 2010. 232 p.

Esta coletânea é introduzida por questionamentos sobre o estudo do espaço organizacional e as metodologias adequadas para esse estudo. Em resposta, os textos desenvolvem conceitos de espaço organizacional que relacionam a dimensão física ou material à dimensão humana e social. São exploradas relações de influência mútua entre, por um lado, espaços organizacionais, identificados como físicos, materiais, construídos, e, por outro lado, pessoas que integram essas organizações, como funcionários e clientes.

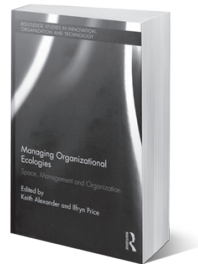

\section{MANAGING ORGANIZATIONAL ECOLOGIES: Space, management, and organizations}

Keith Alexander e Ilfryn Price (Eds.). New York: Routledge, 2012. 266 p.

No campo da Ecologia Humana e sob uma concepção de Facilities Management (FM), este livro focaliza o espaço físico, seu poder e sua influência na organização. O espaço físico intraorganizacional é entendido como uma construção social, ou seja, trata-se de espaço físico-social, tal qual o espaço de relações externas da organização com os stakerholders. 0 espaço organizacional assim concebido se evidencia como importante objeto de gestão.

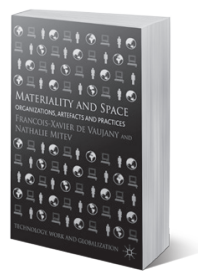

\section{MATERIALITY AND SPACE: Organizations, artefacts and practices}

Francois-Xavier de Vaujany e Nathalie Mitev (Eds.).

Houndsmills: Palgrave Macmillan, 2013. 392 p.

Trata-se de uma coletânea organizada sob a proposta de discutir materialidade e espaço na organização e na gestão organizacional. Os textos apresentam concepções de materialidade na organização e de sociomaterialidade, além de análises de materialidades e espaços no âmbito de organizações e das práticas, inclusive práticas de gestão organizacional. Os diversos conceitos de espaço organizacional são desenvolvidos com ênfase na dimensão social intrinsecamente relacionada à dimensão física.

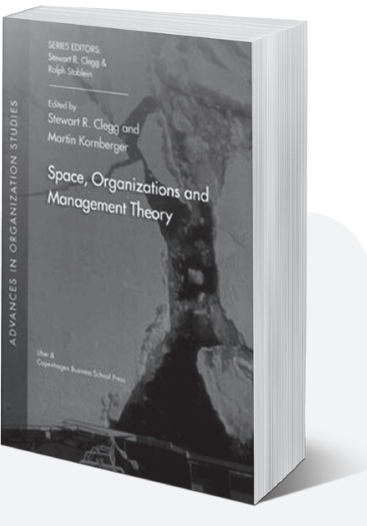

SPACE, ORGANIZATION AND MANAGEMENT THEORY

Stewart Clegg e Martin Kornberger (Eds.). Malmö: Liber; Copenhagen: Copenhagen Business School Press, 2006. $304 \mathrm{p}$.

Esta coletânea foi organizada com o propósito de redescobrir o espaço nos Estudos Organizacionais, sendo essa redescoberta entendida como reinserção e desenvolvimento do conceito nesse campo. Aceitando essa proposta, os textos constituem-se em explorações de relações entre espaço, organização e gestão, que envolvem diversos conceitos de espaço organizacional. Trata-se de processos organizacionais em uma perspectiva espacial e particularmente de relações entre espaço e poder, cultura, mudança e identidade. 